\title{
A Consideration of the Psychological Aspects to Managing Patients with Painful Diabetic Neuropathy: An Insight into Pain Management Services at a Tertiary Centre in the UK
}

Hannah Twiddy $\cdot$ Bernhard Frank $\cdot$ Uazman Alam

Received: September 14, 2020 / Accepted: December 11, 2020 / Published online: December 26, 2020

(C) The Author(s) 2020

\begin{abstract}
Painful diabetic neuropathy (pDN) is characterised by both sensory and affective disturbances, suggesting a complex bidirectional relationship of neuropathic pain and mood disorders. Data on pDN indicate that neuropathic pain reduces quality of life, including mood and physical and social functioning. Depression and pain coping strategies such as catastrophising and social support predict pain severity. There is a significant and reciprocal relationship between depressed mood and increased pain. The key features of assessing people with neuropathic pain in relation to psychological aspects of their health are discussed in the context of management in a
\end{abstract}

H. Twiddy $(\bowtie) \cdot$ B. Frank

Department of Pain Medicine, The Walton Centre, Liverpool, UK

e-mail: Hannah.Twiddy@thewaltoncentre.nhs.uk

U. Alam

Diabetes and Endocrinology Research, Institute of Cardiovascular and Metabolic Medicine and The Pain Research Institute, University of Liverpool and Liverpool University NHS Hospital Trust, Liverpool, UK

\section{U. Alam}

Division of Endocrinology, Diabetes and Gastroenterology, University of Manchester, Manchester, UK tertiary pain management centre (The Walton Centre, Liverpool, UK) including cognitive behavioural interventions amongst others to improve the quality of life in patients with pDN. We consider psychological issues as a factor influencing treatment and outcome in patients with $\mathrm{pDN}$.

Keywords: Acceptance and commitment therapy; Anxiety; Cognitive behavioural therapy; Depression; Painful diabetic neuropathy; Pain management programme 


\section{Key Summary Points}

Why carry out this study?

pDN can result in severe neuropathic pain which is often be intractable. It has an adverse effect on quality of life and social functioning. Psychological factors play an important role in pain perception.

The key features of evaluating people with neuropathic pain in relation to psychological aspects of their health are discussed in the context of management in a tertiary pain management centre. We discuss cognitive behavioural interventions to improve the quality of life in patients with $\mathrm{pDN}$.

\section{What was learned from the study?}

Pain reduction plays only a part of the outcomes in a pain management programme. Quality of life and improvement in overall functioning are key outcomes in psychological interventions.

\section{DIGITAL FEATURES}

This article is published with digital features to facilitate understanding of the article. You can access the digital features on the article's associated Figshare page. To view digital features for this article go to https://doi.org/10.6084/m9. figshare.13352819

\section{INTRODUCTION}

It is well documented that pain is a significant problem in primary care and neuropathic pain represents a tremendous challenge worldwide. It affects a huge proportion of the population, 14 million people in England, according to an audit by the British Pain Society [1].
Clearly, only a proportion of these patients have diabetic neuropathy or pain associated with diabetes; however, whatever its aetiology, pain can cause significant demands on the UK National Health Service (NHS) [2]. Diabetic peripheral polyneuropathy (also known as diabetic neuropathy) affects $50 \%$ of patients with diabetes [3-5] and is an established risk factor for poorer quality of life, and sleep, and symptoms of depression and anxiety [6]. Unfortunately, it is also one of only three independent risk factors for mortality in patients with type 2 diabetes mellitus [7].

There is a significant burden not only financially on health care but also for individuals in terms of the impact on their lifestyles and quality of life as well as their mood [8]. It is of paramount important that we address the needs of this population of patients with pain symptoms given that pain is often perceived as a mere peripheral symptom to a broader disease process. However, the burden on both the individual and society is vast and requires significant attention.

The Walton Centre Pain Management Programme (PMP) service has been in existence for over 30 years and currently holds a registry of patient data to track baseline physical function and psychological distress as well as efficacy of treatments. Since 2014 the PMP service has seen approximately 4500 patients through multidisciplinary assessment clinics and approximately $5 \%$ of these patients have a diagnosis of diabetic neuropathy.

\section{METHODS}

This is a narrative review for the most part based on a lecture provided at the 4th British Symposium on Diabetic Neuropathy (November 2019 held at the University of Liverpool, UK) delivered by Dr. Hannah Twiddy (Research Lead Clinical Psychologist for the Pain Management Programme, The Walton Centre), specifically pertaining to the psychological services provided for patients under the care of The Walton Centre NHS Foundation Trust (Liverpool, UK) PMP. We also undertook a brief literature review on painful diabetic neuropathy (pDN) and psychological interventions/pain management programmes 
using key search terms. A number of publications were retrieved, covering the spectrum from crosssectional studies, cohort studies, randomised controlled trials (RCT), systematic, and thematic reviews. This article is based on previously conducted studies and does not contain any new studies with human participants or animals performed by any of the authors.

\section{RESULTS}

\section{Current Management of pDN}

pDN is a debilitating feature of diabetic neuropathy which results in poor quality of life, functional impairment and morbidity [9]. Current international guidelines advocate the use of pharmacotherapy targeting the pathomechanisms of pain generation in pDN. Moderate improvements in pain are considered to be approximately $30-50 \%$ pain relief, whereas a good outcome is considered greater than $50 \%$ pain relief [10]. Patients should be routinely counselled about the effectiveness of neuropathic pain agents in that only about one in three people will achieve 'good outcomes' [11]. As a result a significant proportion of individuals have significant inadequately control pain and as a result, poor functioning. There is very little focus in international guidelines on delivery of functional improvements through psychological interventions.

For a further review of diabetic neuropathy and treatment of pDN we recommend a review of Iqbal et al. [11] and Alam et al. [10].

\section{Psychosocial Impact in Diabetic Neuropathy}

There is a notable evidence base that discusses the interference on physical and psychological functioning of neuropathic pain in the context and out of the context of diabetes [12, 13]. Indeed, mental comorbidity and sleep disorders are factors associated with $\mathrm{pDN}$ and greater pain intensity, more diabetes complications and lower quality of life [14]. It is not uncommon to assess patients in a tertiary centre and discover comorbid psychological distress. Previous studies have highlighted the magnitude of psychological burden in this population [12, 13]. Vileikyte et al. demonstrated that diabetic neuropathy $(n=338)$ is a risk factor for depression due to $\mathrm{pDN}$ with increased pain, unsteadiness and restrictions in activities of daily living significantly predicting poorer outcomes on the Hospital Anxiety and Depression subscale (HADS-D) over 18 months [15]. Both depression and anxiety are closely related to pain and pain intensity [16, 17]. Additionally, people with moderate-to-severe depressive symptoms are more likely to develop pain [18]. Indeed, Collins et al. suggested that anxiety disorders (32\%) were more prevalent than depression $(22 \%)$ in diabetes [19] which is replicated by other studies in pDN that found anxiety disorders to be as prevalent as depression [20]. The intensity of pain experienced in pDN directly impacts function and increasing intensity of $\mathrm{pDN}$ is associated with increased anxiety and depression. Clearly, there is a complex bidirectional relationship of anxiety/depression and $\mathrm{pDN}$ [20]. As clinical psychologists within the pain management service we conceptualise pain as a causative factor in many mood-related difficulties. Often these factors do not work in a linear fashion, and how we cope with pain can be affected by pre-existing psychological vulnerabilities which forms a part of the assessment process. Primary depressive or anxiety disorder should be treated in the first instance before embarking on psychological interventions for pain; we refer individuals on to the relevant mental health services once the primary issues have been managed.

\section{The Walton Centre PMP Assessment in Clinic}

The Walton Centre PMP meets the aims, method, delivery and outcomes as per the British Pain Society's guidelines for pain management programmes for adults [21], the key points of which are:

1. To improve participation in daily activities of living, enhancing quality of life in people with chronic pain 
2. A variety of methods being utilised by the PMP for directly/indirectly producing behaviour modification, including cognitive and behavioural therapy

3. The standard practice of outcome evaluation such that stakeholders can ascertain participant characteristics and the range of improvements as a result of the PMP, in both the short and longer term

The reduction or relief of pain is not a primary aim of treatment, although improvements in pain are often reported $[22,23]$. The primary focus is to improve daily functioning even in the absence of pain improvement and to shift the behaviour of the participant from inadequate coping with pain and subsequently to focus behaviour on individualised targets which are more worthwhile [21].

Figure 1 and Table 1 highlight the key domains and areas for assessment in patients with persistent pain within the PMP service [24]. Attendance is required at the assessment clinic for $4 \mathrm{~h}$ and patients see four different clinicians: a pain consultant, clinical psychologist, a physiotherapist and an occupational therapist. The patient has about 45 min with each clinician and at the end of the assessment there is a multidisciplinary case conference discussion about clinical presentation from the

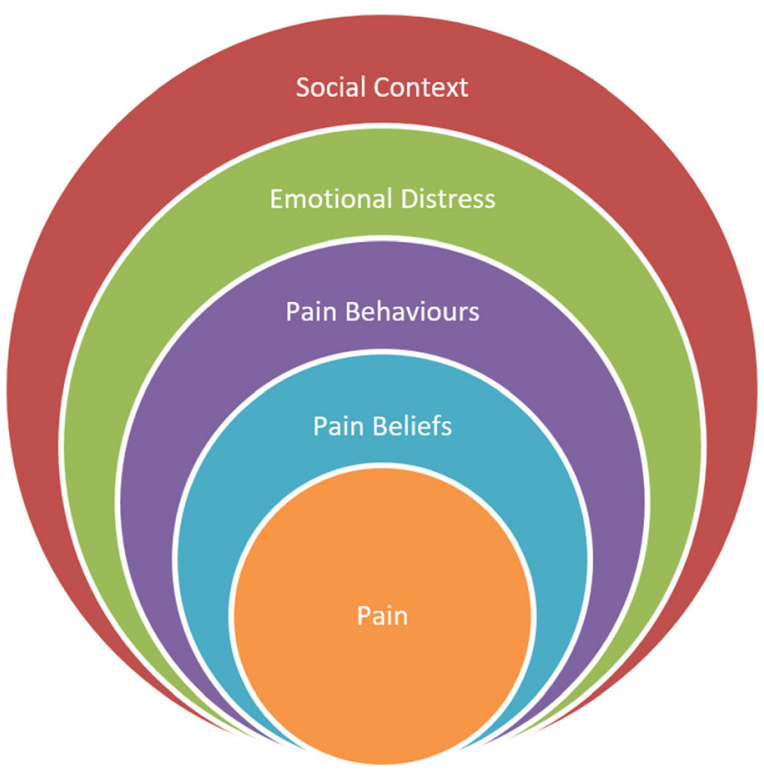

Fig. 1 Domains of impact and areas for assessment different disciplinary perspectives. This includes evaluation of medical, physiotherapy, social mental health-related factors which may impact their presentation. In concluding the clinic, a personalised care package is discussed.

The impact of pain from the four areas highlighted in Table 1 (i.e. biomedical, physiotherapy, occupational therapy and psychology) is significant with varying degrees of input from each. It is important to collect information about day to day life, relationships, employment and social life as much as pain intensity and severity and to establish the significance of mood-related factors in relation to loss of confidence and self-esteem. A major concern of patients is the notion that others disbelieve the pain symptoms, symptoms are exaggerated or are indicative of health anxiety or psychosomatic complaints. It can be difficult to conceptualise the pain for patients. The use of metaphors and analogies can help individuals to understand; it is also key to move away from lists of symptoms such as burning, throbbing, tingling pulsating and focus on-'ok you have those symptoms, tell me about how those symptoms impact across these domains...'.

Psychologists working in chronic pain gather information regarding an individual's locus of control [25]; how much does the individual feel that they can be an agent in bringing about change in their circumstances? This is broadly more relevant to diabetes in terms of treatment adherence and the ability and capability to effectively manage physical wellbeing. In chronic pain, it relates to self-efficacy, a feeling of being effective in managing symptoms and pain intensity [26]. The feeling that patients have an internal locus of control can result in a positive outlook of 'I can bring about change to my life', as opposed to a negative outlook of 'I am going to wait here until something external happens to help me to improve my life'. In patients with an external locus of control and low levels of pain-related self-efficacy, we may consider that a number of factors could thwart self-management approaches.

The PMP consists of both behavioural and cognitive techniques; in addition, physical exercise and education are also part of the processes of delivery. Previous studies have shown 
Table 1 Key areas for biopsychosocial assessment [57]

\begin{tabular}{|c|c|c|c|}
\hline Biomedical aspects & Physiotherapy aspects & $\begin{array}{l}\text { Occupational } \\
\text { therapy aspects }\end{array}$ & Psychology aspects \\
\hline Nature of the pain condition & Level of physical deconditioning & $\begin{array}{l}\text { Impact of pain } \\
\text { across all } \\
\text { occupational } \\
\text { domains }\end{array}$ & $\begin{array}{l}\text { Current psychological } \\
\text { symptoms }\end{array}$ \\
\hline Aetiology of pain & $\begin{array}{l}\text { What is an appropriate level of } \\
\text { physical activity? }\end{array}$ & $\begin{array}{l}\text { Day to day routine } \\
\text { and structure }\end{array}$ & $\begin{array}{l}\text { Impact of pain on mood } \\
\text { and activity }\end{array}$ \\
\hline Physical prognosis & $\begin{array}{l}\text { Is there evidence of overly } \\
\text { restricted movement associated } \\
\text { with fear avoidance? }\end{array}$ & Aids and adaptations & $\begin{array}{l}\text { Pain beliefs and } \\
\text { behaviours-including } \\
\text { fear and avoidance }\end{array}$ \\
\hline $\begin{array}{l}\text { Need for further medical or } \\
\text { surgical interventions and } \\
\text { medication side effects }\end{array}$ & $\begin{array}{l}\text { Are there outstanding issues } \\
\text { requiring further medical review? }\end{array}$ & $\begin{array}{l}\text { Goals and value-led } \\
\text { activities }\end{array}$ & Prior psychiatric history \\
\hline \multirow[t]{3}{*}{$\begin{array}{l}\text { Is the pain medically } \\
\text { proportionate and/or makes } \\
\text { organic sense? }\end{array}$} & & Pacing & $\begin{array}{l}\text { Treatment adherence in } \\
\text { other comorbidities }\end{array}$ \\
\hline & & & Iatrogenic distress \\
\hline & & & $\begin{array}{l}\text { Motivation to change and } \\
\text { locus of control }\end{array}$ \\
\hline
\end{tabular}

the effectiveness of PMP interventions. In a meta-analysis of 11 studies, treatment gains across pain perceptions were maintained at 12 months post-treatment and provided evidence for long-term efficacy of PMP interventions [27]. An early systematic review in 1999 [28], which was subsequently updated in 2012 as a Cochrane review [29], concluded that Cognitive Behavioral Therapy (CBT) (on which PMPs are based) is an effective intervention in the armoury of the management of chronic pain. Other studies have drawn similar conclusions in mixed pain groups [30, 31]. As with other studies the benefits are greatest in psychological functioning measures. The residential INPUT Pain Management Unit reported clinically significant improvement in pain and psychological measures by $19-55 \%$ at posttreatment and $17-44 \%$ at 9 -month follow-up.
We detail psychological treatments and interventions in our PMP in more detail below.

\section{Psychological Treatments}

In the same manner that the assessment of neuropathic pain takes a biopsychosocial approach, the objective of psychologically led interventions is not only the reduction in pain but improvement in quality of life and moodrelated measures [32]; some measures included are the Beck Depression Inventory (BDI-II), chronic pain acceptance questionnaire (CPAQ), pain-related self-efficacy questionnaire and the pain catastrophising questionnaire. Patients with both neuropathic and musculoskeletal conditions attend for psychological interventions at The Walton Centre PMP service. However, there are some factors, from a 
psychological perspective, that are relevant when we consider the differences between the underlying pain types. Patients with neuropathic pain often describe allodynia, which makes their presentation different than musculoskeletal pain, as the pain is less predictable. Musculoskeletal disease pain can be readily amenable to physical exercise, whereas neuropathic pain conditions including $\mathrm{pDN}$ are less so, although some benefit may still occur with exercise [33]. Modifications to the introduction to the importance of physiotherapy, in terms of helping people to modulate movement in neuropathic pain conditions, can be vital [34].

Neuropathic pain needs to be considered in the context of other comorbidities, such as diabetes. Poor management of pain may itself impact treatment adherence and management of other physical conditions, whereas improving neuropathic pain may promote improvements in glycaemic control [35]. For instance, in a database analysis of approximately 4300 people with diabetes, patients who were adherent to $\mathrm{pDN}$ medications were more adherent to oral antidiabetic medications [36]. There is evidence to suggest that there is poorer glycaemic control in individuals with pDN [37]. Pai et al. [37] showed that increased postprandial glycaemic exposure, as assessed by high glycated haemoglobin (HbA1c) and near-normal fasting plasma glucose levels, is associated with an increased risk of $\mathrm{pDN}$ in type 2 diabetes. Unfortunately, complications of diabetes are also associated with psychological comorbidities. In a longitudinal cohort $(n=4623)$ of patients with type 2 diabetes followed up from 2000-2002 to 2005-2007, major depression was associated with significantly higher risks of adverse microvascular outcomes [hazard ratio $1.36(95 \%$ CI 1.05-1.75)] and adverse macrovascular outcomes $\quad\left[\begin{array}{llll}1.24 & (95 \% & \text { CI }\end{array}\right.$ 1.0-1.54)] after adjustment for prior complications and clinical/demographic, and diabetes self-care variables [38]. Similar findings were also noted in the DIACET study conducted in an over 65 years population in Japan $(n=4283)$ where a higher Patient Health Questionnaire-9 (PHQ-9) was associated with increased odds ratios for retinopathy, symptoms related to peripheral neuropathy and autonomic neuropathy, and end-stage renal disease requiring dialysis after adjustment for clinical and demographic factors and HbA1c [39]. A systematic review (22 studies) and meta-analysis (11 studies) of depression was associated with an increased risk of both incident macrovascular (hazard ratio 1.38; 95\% CI 1.30-1.47) and microvascular disease (hazard ratio $1.33 ; 95 \%$ CI 1.25-1.41). Additionally, two studies $(n=230,000) \quad$ examining baseline diabetes complications were suitable for meta-analysis and showed an increased risk of incident depressive disorder (hazard ratio 1.14; 95\% CI 1.07-1.21).

There are two treatment modalities in PMP: individual and group based. The format of group-based PMPs follows the multidisciplinary guidelines set out in the British Pain Society guidelines. At The Walton Centre the two main groups are run over either 16 days or 5 days over 6-week periods [40].

Acceptance and commitment therapy (ACT) is a psychological modality that has been used with increasing interest in chronic pain. It is considered a third-wave of CBT and can be used alongside more traditional CBT [41-43]. Traditional CBT approaches are focused on identifying thoughts, feelings and behaviours that may drive and maintain presenting psychological difficulties. In the context of chronic pain the focus is often around pain beliefs, e.g. the origin of my pain is sinister or will harm me, and the associated behavioural response. At The Walton Centre, it is through supporting individuals to identify unhelpful patterns and responses that change to habituated patterns and subsequent mood disturbance can be addressed. ACT utilises acceptance and mindfulness strategies along with commitment to behaviour change to support individuals to develop psychological flexibility; an individual's ability to respond to changing demands and alterations in emotions. In the case of chronic pain, strategies are focused on learning to live effectively and alongside pain, an unpleasant experience, through identifying value-led behaviour change and mindful approaches. It can be provided on a one-to-one basis if deemed necessary. A recent study of 50 individuals with pDN based in Iran 
showed improved pain acceptance following intervention after 3 months [41].

Considering the generalisability of psychological approaches to a primary care population, a Brief Cognitive Behavioural Therapy for Chronic Pain (Brief CBT-CP) delivered in a community setting in the USA showed improvements in pain intensity but importantly improvements in functional limitations and pain-related efficacy outcomes [44]. Adapted approaches such as the Brief CBT-CP are eminently feasible in a community setting; however, this will clearly require restructuring of services and community and/or ambulatory psychological input which are generally underdeveloped [45].

\section{Outcomes}

Monitoring outcomes is key to assessing the efficacy of self-management approaches in chronic pain. At The Walton Centre a range of psychometrics and physical function measures are collected across domains [32]. These are namely:

Beck's Depression Inventory 2nd Edition (BDI-II) consists of 21 items to assess the intensity of depression in both clinical and non-clinical populations [46]. The BDI-II was developed to correspond to Diagnostic and Statistical Manual of Mental Disorders IV (DSM-IV) criteria for diagnosing depressive disorders. Given the high prevalence of depression in individuals with chronic pain and the negative outcomes

Table 2 Clinically meaningful change after PMP (The Walton Centre internal audit-unpublished)

\begin{tabular}{ll}
\hline $\begin{array}{l}\text { Measure of clinical } \\
\text { outcome }\end{array}$ & $\begin{array}{l}\text { Percentage achieving clinically } \\
\text { meaningful change }\end{array}$ \\
\hline Depression & $60 \%$ \\
Pain acceptance & $72 \%$ \\
Pain intensity & $37 \%$ \\
Pain catastrophising & $63 \%$ \\
Disability & $44 \%$ \\
questionnaire & \\
\hline
\end{tabular}

associated with such comorbidity, the importance of assessing depressive symptoms is widely acknowledged by chronic pain specialists.

Pain Catastrophising Scale (PCS) is a 13-item self-report measure designed to assess catastrophic thoughts or feelings accompanying the experience of pain [47]. The questionnaire uses a 5-point scale ranging from 0 (not at all) to 4 (all the time). Pain catastrophising affects how individuals experience pain. People who catastrophise tend to do three things. They ruminate about their pain ('I can't stop thinking about how much this hurts'), they magnify their pain (e.g. 'I'm afraid that something serious might happen'), and they feel helpless to manage their pain ('there is nothing I can do to reduce the intensity of my pain').

Pain Self-Efficacy Questionnaire (PSEQ) is a 10-item questionnaire, developed to assess the confidence people with ongoing pain have in performing activities while in pain [48]. The PSEQ is applicable to all persisting pain presentations, covering a range of functions, including household chores, socialising, work, as well as coping with pain without medication.

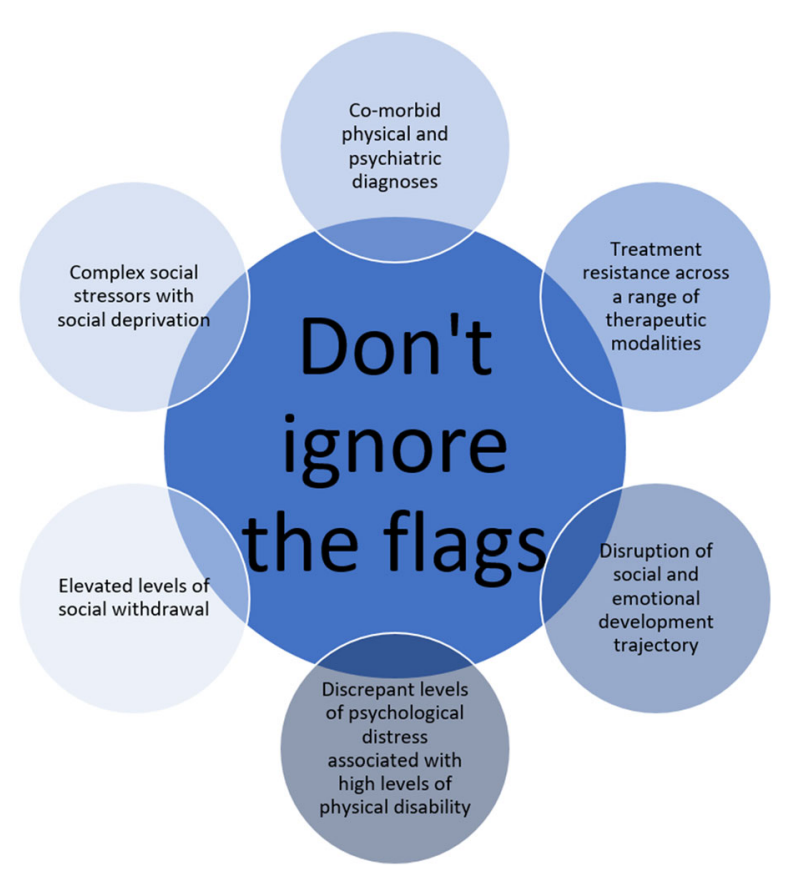

Fig. 2 Key areas for consideration in clinical practice to enhance a biopsychosocial approach 
Table 3 Highlights key areas with common "dos and don'ts": practical tips for medical practitioners to identify psychosocial red flags

\begin{tabular}{|c|c|c|}
\hline Practical tip & Dos & Don'ts \\
\hline Develop rapport & $\begin{array}{l}\text { Listen and validate physical symptoms } \\
\text { Gently acknowledge the emotional impact } \\
\text { of living with pain and the broader } \\
\text { quality of life issues that could benefit } \\
\text { equally from attention }\end{array}$ & $\begin{array}{l}\text { Advise the patient that persistent pains can } \\
\text { be caused by psychological problems or } \\
\text { trauma }\end{array}$ \\
\hline Signpost & $\begin{array}{l}\text { Consider referring the patient on to } \\
\text { clinical health psychology services or ask } \\
\text { the GP to refer on to local service } \\
\text { provisions }\end{array}$ & $\begin{array}{l}\text { Try to manage the patient's psychological } \\
\text { issues independently if they need expert } \\
\text { opinion e.g. "exercise for a better mood", } \\
\text { "think about all the positive things" } \\
\text { Discharge them with no biopsychosocial } \\
\text { plan or reference in your clinical } \\
\text { correspondence to primary care that you } \\
\text { have observed mood-related difficulties in } \\
\text { the context of physical symptoms }\end{array}$ \\
\hline $\begin{array}{l}\text { Consider relevant systemic } \\
\text { factors and build up a picture } \\
\text { of holistic wellbeing }\end{array}$ & $\begin{array}{l}\text { Enquire about treatment adherence in } \\
\text { other comorbid health conditions } \\
\text { Consider the age of the patient and the } \\
\text { specific difficulties pain may have on life } \\
\text { stage e.g. career/education/starting a } \\
\text { family }\end{array}$ & \\
\hline $\begin{array}{l}\text { Observe and make note of any } \\
\text { discrepancies between } \\
\text { physical disability/pain and } \\
\text { distress }\end{array}$ & $\begin{array}{l}\text { Ask patients to rate on a visual analogue } \\
\text { scale }(0-10) \text { the level of pain distress/ } \\
\text { intensity and disability they experience- } \\
\text { make note if pain intensity is high but } \\
\text { distress is low and consider onward } \\
\text { referral to psychological services }\end{array}$ & \\
\hline $\begin{array}{l}\text { Communication style and } \\
\text { language }\end{array}$ & $\begin{array}{l}\text { Use accurate and clear language. Reduce } \\
\text { the risk of misunderstandings by } \\
\text { ensuring that the patient understands } \\
\text { accurately what you have advised } \\
\text { Ask the patient at the end if they need any } \\
\text { aspects to be clarified or anything has } \\
\text { caused undue concern }\end{array}$ & $\begin{array}{l}\text { Avoid vivid and distressing analogies of } \\
\text { structural problems } \\
\text { Avoid unhelpful and potentially inaccurate } \\
\text { predictions of physical prognosis }\end{array}$ \\
\hline
\end{tabular}

Self-efficacy beliefs in people with chronic pain have been assessed either by reference to confidence in ability to perform specific tasks or confidence in performing more generalised constructs such as coping with pain.

Pain intensity is rated from 0 (no pain) to 10 (the most intense pain imaginable), taking into 
account how you have felt over the last week. This commonly used method of rating pain intensity is reliable and valid, and no one scale consistently demonstrates greater responsiveness in detecting improvements associated with pain treatment [49].

In addition to the measures stated above, a number of tools have been utilised and validated to screen depression (PHQ-9 [50, 51], HADS $[52,53])$ and anxiety (HADS [52], Generalised Anxiety Disorder 7-item scale (GAD-7) $[54,55])$ in diabetes. However, there is a word of caution: these instruments are not diagnostic but should be used for screening purposes [56] as elevated scores can be as a result of diabetes symptomatology.

Table 2 highlights the average percentage of patients who achieve clinically significant change on PMPs (data based on more than 4500 patients from a clinical audit at The Walton Centre-unpublished).

Whilst it is the job of a registered psychologist to identify specific psychological needs and possible mental health diagnoses, there are some things that non-psychological practitioners can helpfully do to help mitigate problems, and also signpost on when necessary.

The take-home messages include validate pain, which means acknowledge it is real and is impacting on the individual's quality of life. Even though it might be peripheral to a broader diagnosis that requires management by you a non-pain specialist, it is key to validate the pain experience. Consider the treatments offeredare they all biomedical, do they need some psychological input? Evaluate if the patient has any psychosocial red flags (Fig. 2; Table 3). In addition:

1. Are the patient's expectations realistic?

2. Are there expectations of the complete relief of pain?

3. Do they hope for this/a magical treatment?

4. Could language used by health-care professional possibly be feeding into misperceptions?

5. Is a referral to mental health or multidisciplinary pain team appropriate?

\section{CONCLUSION}

It is important to consider the holistic presentation of patients reporting persistent pain in the context of pDN. Ongoing referrals may be necessary to optimise outcomes, particularly if psychosocial factors are at play. Pain reduction is not the primary objective of pain management approaches and patients should be encouraged to consider issues of quality of life and goals associated with such areas.

\section{ACKNOWLEDGEMENTS}

Funding. No funding or sponsorship was received for this study or publication of this article.

Authorship. All named authors meet the International Committee of Medical Journal Editors (ICMJE) criteria for authorship for this article, take responsibility for the integrity of the work as a whole, and have given their approval for this version to be published.

Disclosures. Hannah Twiddy, Bernhard Frank and Uazman Alam have nothing to disclose.

Compliance with Ethics Guidelines. This article is based on previously conducted studies and does not contain any new studies with human participants or animals performed by any of the authors.

Data Availability. Data sharing is not applicable to this article as no datasets were generated or analyzed during the current study.

Open Access. This article is licensed under a Creative Commons Attribution-NonCommercial 4.0 International License, which permits any non-commercial use, sharing, adaptation, distribution and reproduction in any medium or format, as long as you give appropriate credit to the original author(s) and the source, provide a link to the Creative Commons licence, and indicate if changes were made. The images or 
other third party material in this article are included in the article's Creative Commons licence, unless indicated otherwise in a credit line to the material. If material is not included in the article's Creative Commons licence and your intended use is not permitted by statutory regulation or exceeds the permitted use, you will need to obtain permission directly from the copyright holder. To view a copy of this licence, visit http://creativecommons.org/licenses/by$\mathrm{nc} / 4.0 /$.

\section{REFERENCES}

1. Price C, de C Williams AC, Smith BH, Bottle A. The National Pain Audit for specialist pain services in England and Wales 2010-2014. Br J Pain. 2018;13(3):185-93.

2. Berger A, Dukes EM, Oster G. Clinical characteristics and economic costs of patients with painful neuropathic disorders. J Pain. 2004;5(3):143-9.

3. Dyck PJ, Kratz KM, Karnes JL, et al. The prevalence by staged severity of various types of diabetic neuropathy, retinopathy, and nephropathy in a population-based cohort: the Rochester Diabetic Neuropathy Study. Neurology. 1993;43(4):817-24.

4. Abbott CA, Malik RA, van Ross ERE, Kulkarni J, Boulton AJM. Prevalence and characteristics of painful diabetic neuropathy in a large communitybased diabetic population in the U.K. Diabetes Care. 2011;34(10):2220-4.

5. Young MJ, Boulton AJ, MacLeod AF, Williams DR, Sonksen PH. A multicentre study of the prevalence of diabetic peripheral neuropathy in the United Kingdom hospital clinic population. Diabetologia. 1993;36(2):150-4.

6. Gylfadottir SS, Christensen DH, Nicolaisen SK, et al. Diabetic polyneuropathy and pain, prevalence, and patient characteristics: a cross-sectional questionnaire study of 5,514 patients with recently diagnosed type 2 diabetes. Pain. 2020;161(3):574-83.

7. Calles-Escandon J, Lovato LC, Simons-Morton DG, et al. Effect of intensive compared with standard glycemia treatment strategies on mortality by baseline subgroup characteristics: the Action to Control Cardiovascular Risk in Diabetes (ACCORD) trial. Diabetes Care. 2010;33(4):721-7.

8. daCosta DM, Cappelleri JC, Joshi AV. A longitudinal assessment of painful diabetic peripheral neuropathy on health status, productivity, and health care utilization and cost. Pain Med. 2011;12(1):118-26.

9. Boulton A, Malik R, Arezzo J, Sosenko J. Diabetic somatic neuropathies. Diabetes Care. 2004;27(6): 1458-86.

10. Alam U, Sloan G, Tesfaye S. Treating pain in diabetic neuropathy: current and developmental drugs. Drugs. 2020;80(4):363-84.

11. Iqbal Z, Azmi S, Yadav R, et al. Diabetic peripheral neuropathy: epidemiology, diagnosis, and pharmacotherapy. Clin Ther. 2018;40(6):828-49.

12. Torta R, Ieraci V, Zizzi F. A review of the emotional aspects of neuropathic pain: from comorbidity to co-pathogenesis. Pain Ther. 2017;6(Suppl 1):11-7.

13. Meyer-Rosberg K, Kvarnström A, Kinnman E, Gordh T, Nordfors LO, Kristofferson A. Peripheral neuropathic pain-a multidimensional burden for patients. Eur J Pain. 2001;5(4):379-89.

14. Naranjo C, Ortega-Jiménez P, Del Reguero L, Moratalla G, Failde I. Relationship between diabetic neuropathic pain and comorbidity. Their impact on pain intensity, diabetes complications and quality of life in patients with type- 2 diabetes mellitus. Diabetes Res Clin Pract. 2020;165:108236.

15. Vileikyte L, Peyrot M, Gonzalez JS, et al. Predictors of depressive symptoms in persons with diabetic peripheral neuropathy: a longitudinal study. Diabetologia. 2009;52(7):1265-73.

16. Fishbain DA, Cutler R, Rosomoff HL, Rosomoff RS. Chronic pain-associated depression: antecedent or consequence of chronic pain? A review. Clin J Pain. 1997;13(2):116-37.

17. McWilliams LA, Cox BJ, Enns MW. Mood and anxiety disorders associated with chronic pain: an examination in a nationally representative sample. Pain. 2003;106(1-2):127-33.

18. Von Korff M, Le Resche L, Dworkin SF. First onset of common pain symptoms: a prospective study of depression as a risk factor. Pain. 1993;55(2):251-8.

19. Collins MM, Corcoran P, Perry IJ. Anxiety and depression symptoms in patients with diabetes. Diabet Med. 2009;26(2):153-61.

20. Gore M, Brandenburg NA, Dukes E, Hoffman DL, Tai K-S, Stacey B. Pain severity in diabetic peripheral neuropathy is associated with patient functioning, symptom levels of anxiety and depression, and sleep. J Pain Symptom Manage. 2005;30(4):374-85. 
21. BPS. Guidelines for pain management programmes for adults 2013. https://www.britishpainsociety. org/static/uploads/resources/files/pmp2013_main_ FINAL_v6.pdf. Accessed 26 Nov 2020.

22. van Tulder MW, Ostelo R, Vlaeyen JW, Linton SJ, Morley SJ, Assendelft WJ. Behavioral treatment for chronic low back pain: a systematic review within the framework of the Cochrane Back Review Group. Spine (Phila Pa 1976). 2000;25(20):2688-99.

23. Guzmán J, Esmail R, Karjalainen K, Malmivaara A, Irvin E, Bombardier C. Multidisciplinary rehabilitation for chronic low back pain: systematic review. BMJ. 2001;322(7301):1511-6.

24. Loeser JD, Melzack R. Pain: an overview. Lancet. 1999;353(9164):1607-9.

25. Cano-García FJ, Rodríguez-Franco L, López-Jiménez AM. Locus of control patterns in headaches and chronic pain. Pain Res Manag. 2013;18(4):e48-54.

26. Jackson T, Wang Y, Wang Y, Fan H. Self-efficacy and chronic pain outcomes: a meta-analytic review. J Pain. 2014;15(8):800-14.

27. Chipchase L, Sheffield DP, Hill P. The long-term effectiveness of pain management programs: a systematic review and meta-analysis. J Pain Manag. 2012;5(3):215-30.

28. Morley S, Eccleston C, Williams A. Systematic review and meta-analysis of randomized controlled trials of cognitive behaviour therapy and behaviour therapy for chronic pain in adults, excluding headache. Pain. 1999;80(1):1-13.

29. Williams AC, Eccleston C, Morley S. Psychological therapies for the management of chronic pain (excluding headache) in adults. Cochrane Database Syst Rev. 2012;11(11):Cd007407.

30. Inoue $\mathrm{M}$, Inoue $\mathrm{S}$, Ikemoto $\mathrm{T}$, et al. The efficacy of a multidisciplinary group program for patients with refractory chronic pain. Pain Res Manage. 2014;19(6):302-8.

31. Smith JG, Knight L, Stewart A, Smith EL, McCracken LM. Clinical effectiveness of a residential pain management programme-comparing a large recent sample with previously published outcome data. Br J Pain. 2016;10(1):46-58.

32. Dworkin RH, Turk DC, Farrar JT, et al. Core outcome measures for chronic pain clinical trials: IMMPACT recommendations. Pain. 2005;113(1-2): 9-19.

33. Cooper MA, Kluding PM, Wright DE. Emerging relationships between exercise, sensory nerves, and neuropathic pain. Front Neurosci. 2016;10:372.
34. Akyuz G, Kenis O. Physical therapy modalities and rehabilitation techniques in the management of neuropathic pain. Am J Phys Med Rehabil. 2014;93(3):253-9.

35. Hardy T, Sachson R, Shen S, Armbruster M, Boulton AJ. Does treatment with duloxetine for neuropathic pain impact glycemic control? Diabetes Care. 2007;30(1):21-6.

36. Oladapo AO, Barner JC, Rascati KL, Strassels SA. A retrospective database analysis of neuropathic pain and oral antidiabetic medication use and adherence among Texas adults with type 2 diabetes enrolled in Medicaid. Clin Ther. 2012;34(3):605-13.

37. Pai YW, Tang CL, Lin CH, Lin SY, Lee IT, Chang MH. Glycaemic control for painful diabetic peripheral neuropathy is more than fasting plasma glucose and glycated haemoglobin. Diabetes Metab. 2020 .

38. Lin EH, Rutter CM, Katon W, et al. Depression and advanced complications of diabetes: a prospective cohort study. Diabetes Care. 2010;33(2):264-9.

39. Ishizawa K, Babazono T, Horiba $\mathrm{Y}$, et al. The relationship between depressive symptoms and diabetic complications in elderly patients with diabetes: analysis using the Diabetes Study from the Center of Tokyo Women's Medical University (DIACET). J Diabetes Comp. 2016;30(4):597-602.

40. Daniel HC, Narewska J, Serpell M, Hoggart B, Johnson R, Rice AS. Comparison of psychological and physical function in neuropathic pain and nociceptive pain: implications for cognitive behavioral pain management programs. Eur J Pain. 2008;12(6):731-41.

41. Taheri AA, Foroughi AA, Mohammadian Y, et al. The effectiveness of acceptance and commitment therapy on pain acceptance and pain perception in patients with painful diabetic neuropathy: a randomized controlled trial. Diabetes Ther. 2020;11(8): 1695-1708.

42. McCracken LM, Vowles KE. Acceptance and commitment therapy and mindfulness for chronic pain: model, process, and progress. Am Psychol. 2014;69(2):178-87.

43. Wetering EJ, Lemmens KM, Nieboer AP, Huijsman R. Cognitive and behavioral interventions for the management of chronic neuropathic pain in adults_a systematic review. Eur J Pain. 2010;14(7): 670-81.

44. Beehler GP, Murphy JL, King PR, et al. Brief cognitive behavioral therapy for chronic pain: results from a clinical demonstration project in primary 
care behavioral health. Clin J Pain. 2019;35(10): 809-17.

45. Burton M, Boyle S, Psy CHDC, Kagan C. Community psychology in Britain. In: Reich SM, Riemer M, Prilleltensky I, Montero M, editors. International community psychology: history and theories. Boston, MA: Springer US; 2007. p. 219-37.

46. Arnarson TO, Olason DT, Smári J, Sigurethsson JF. The Beck depression inventory second edition (BDIII): psychometric properties in Icelandic student and patient populations. Nord J Psychiatry. 2008;62(5):360-5.

47. Sullivan MJL, Bishop SR, Pivik J. The pain catastrophizing scale: development and validation. Psychol Assess. 1995;7(4):524-32.

48. Nicholas MK. The pain self-efficacy questionnaire: taking pain into account. Eur J Pain. 2007;11(2): 153-63.

49. Jensen MP, Karoly P. Self-report scales and procedures for assessing pain in adults. Handbook of pain assessment, 2nd ed. New York, NY, US: Guilford Press; 2001. p. 15-34.

50. Acee AM. Detecting and managing depression in type II diabetes: PHQ-9 is the answer! Medsurg Nurs. 2010;19(1):32-8.
51. van Steenbergen-Weijenburg KM, de Vroege L, Ploeger RR, et al. Validation of the PHQ-9 as a screening instrument for depression in diabetes patients in specialized outpatient clinics. BMC Health Serv Res. 2010;10:235

52. Brennan C, Worrall-Davies A, McMillan D, Gilbody S, House A. The hospital anxiety and depression scale: a diagnostic meta-analysis of case-finding ability. J Psychosom Res. 2010;69(4):371-8.

53. Lloyd CE, Dyer PH, Barnett AH. Prevalence of symptoms of depression and anxiety in a diabetes clinic population. Diabet Med. 2000;17(3):198-202.

54. Spitzer RL, Kroenke K, Williams JB, Löwe B. A brief measure for assessing generalized anxiety disorder: the GAD-7. Arch Intern Med. 2006;166(10):1092-7.

55. Löwe B, Decker O, Müller S, et al. Validation and standardization of the generalized anxiety disorder screener (GAD-7) in the general population. Med Care. 2008;46(3):266-74.

56. Reddy P, Philpot B, Ford D, Dunbar JA. Identification of depression in diabetes: the efficacy of PHQ-9 and HADS-D. Br J Gen Pract. 2010;60(575):e239-45.

57. Darnall BD, Carr DB, Schatman ME. Pain psychology and the biopsychosocial model of pain treatment: ethical imperatives and social responsibility. Pain Med. 2017;18(8):1413-5. 